\title{
Cardiovascular Diseases and Panax ginseng: A Review on Molecular Mechanisms and Medical Applications
}

\author{
Jong-Hoon Kim* \\ Department of Veterinary Physiology, College of Veterinary Medicine, Biosafety Research Institute, Chonbuk National \\ University, Jeonju 561-756, Korea
}

Ginseng is one of the most widely used herbal medicines and is reported to have a wide range of therapeutic and pharmacological applications. Ginseng may also be potentially valuable in treating cardiovascular diseases. Research concerning cardiovascular disease is focusing on purified individual ginsenoside constituents of ginseng to reveal specific mechanisms instead of using whole ginseng extracts. The most commonly studied ginsenosides are $\mathrm{Rb}_{1}, \mathrm{Rg}_{1}, \mathrm{Rg}_{3}, \mathrm{Rh}_{1}, \mathrm{Re}$, and $\mathrm{Rd}$. The molecular mechanisms and medical applications of ginsenosides in the treatment of cardiovascular disease have attracted much attention and been the subject of numerous publications. Here, we review the current literature on the myriad pharmacological functions and the potential benefits of ginseng in this area. In vitro investigations using cell cultures and in vivo animal models have indicated ginseng's potential cardiovascular benefits through diverse mechanisms that include antioxidation, modifying vasomotor function, reducing platelet adhesion, influencing ion channels, altering autonomic neurotransmitters release, and improving lipid profiles. Some 40 ginsenosides have been identified. Each may have different effects in pharmacology and mechanisms due to their different chemical structures. This review also summarizes results of relevant clinical trials regarding the cardiovascular effects of ginseng, particularly in the management of hypertension and improving cardiovascular function.

Keywords: Panax ginseng, Cardiovascular disease(CVD), Myocardial ischemia, Vasomotor tone, Lipid profile, Antioxidants

\section{INTRODUCTION}

Cardiovascular disease (CVD) is an important problem among the 400 million indigenous populations around the world, and have been included in the World Health Organization '2008-2013 Action plan for noncommunicable diseases' [1]. CVD, which encompasses a spectrum of diseases including coronary artery disease, peripheral vascular disease, congestive heart failure, dyslipidemias, and hypertension, affects millions of Americans and is perennial among the leading causes of morbidity and mortality [2]. These diseases are common and occur in infants, children, and adults of both genders, affecting people of all races and ethnicities. The lifetime

(c) This is an Open Access article distributed under the terms of the Creative Commons Attribution Non-Commercial License (http://creativecommons.org/licenses/by-nc/3.0/) which permits unrestricted non-commercial use, distribution, and reproduction in any medium, provided the original work is properly cited. risk for a 40-year-old developing coronary heart disease is roughly $50 \%$ for men and $32 \%$ for women [3]. Over the past 50 years, it has become clear that the cascade of thrombotic events following atherosclerotic plaque rupture causes occlusion of the coronary artery, which interrupts the supply of blood and oxygen to the myocardium, resulting in infarction. Myocardial necrosis following infarction is followed by heart failure, myocardial rupture, or arrhythmia [4]. Despite enormous strides in the last five decades, myocardial infarction, stroke, and sudden death remain the principal causes of morbidity and mortality in industrialized nations. Among the most

\footnotetext{
Received 14 Oct. 2011, Revised 14 Dec. 2011, Accepted 14 Dec. 2011

*Corresponding author

E-mail: jhkim1@chonbuk.ac.kr

Tel: +82-63-270-2563, Fax: +82-63-270-3780
} 


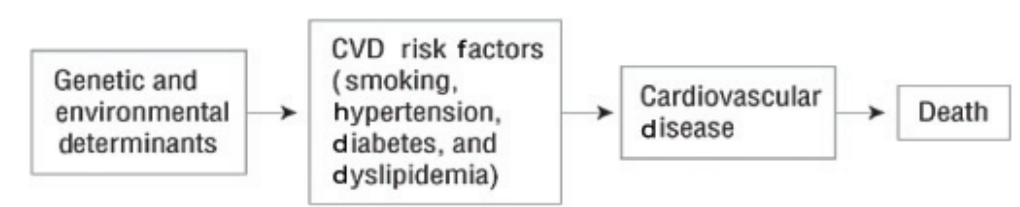

Fig. 1. Pathway relating cardiovascular disease (CVD) mortality. The established CVD risk factors lie in the middle of a chain of events that leads to cardiac death.

important of these CVD are dyslipidemia, hypertension, age, smoking status, insulin resistance, diabetes mellitus, and family history for premature coronary artery disease [5]. Also, atherosclerosis and acute coronary syndrome are now recognized as manifestations of vascular inflammation [6,7]. Risk factors for CVD promote endothelial dysfunction. Dysfunctional endothelial cells express adhesion molecules, which promote the binding and influx of inflammatory white blood cells (T-cells and mast cells) into the subendothelial space [8]. White blood cells produce interleukins, cytokines, and reactive oxygen species, which create an inflammatory focus within the arterial wall. Atherogenic lipoproteins such as lowdensity lipoprotein access the subendothelial space where they become trapped within the network of intercellular matrix proteins and undergo enzymatic oxidative modification, aggregation, and, ultimately, uptake by macrophages. This process leads to the development of foam cells $[9,10]$.

Heart disease is the leading cause of death among all ages, and cardiac infarction remains the major cause of death (Fig. 1) [11,12]. This is the foremost reason why CVD is a major area of longevity research.

Ginseng has been used for over 2,000 years, in the belief that it is a panacea and promotes longevity. Panax ginseng is a traditional medicinal plant that has been used therapeutically for millennia in the Orient. Particularly in Korea, China, and Japan, it is the most valuable of all medicinal herbs. The name Panax means 'all healing,' which describes the traditional belief that ginseng has properties to heal all aspects of the body. The most common ginsengs are Korean red ginseng $(P$. ginseng Meyer), Chinese ginseng ( $P$. notoginseng) and American ginseng (P. quinquefolium L.). Despite this rich history, the basis of the plant's medicinal prowess was unknown until the isolation of the active constituents (ginsenosides) beginning in 1963 [13,14]. Much effort has since been focused on evaluating the function and elucidating the molecular mechanism of each ginsenoside. This is reflected in the exploding number of PubMed cited publications on ginseng and ginsenosides since 1975 . Research now focuses on the study of purified individual ginsenosides instead of using whole ginseng root [15-
20]. Each ginsenoside may have different pharmacologic effect(s) and mechanism(s) reflective of their different structures. Approximately 40 ginsenosides have been identified as of 2012, and the various methods of separation and analysis are well-reviewed [21]. The most commonly studied ginsenosides are $\mathrm{Rb}_{1}, \mathrm{Rg}_{1}, \mathrm{Rg}_{3}, \mathrm{Re}$, and $\mathrm{Rd}$. A detailed review about the anti-amnestic and antiaging effects and action mechanisms of $R b_{1}$ and $R g_{1}$ has been published [20].

Moreover, ginseng and its ginsenoside constituents are thought to possess vasorelaxation, anti-oxidation, anti-inflammation, and anti-cancer activities. Ginsenosides also showed the effects on the central nervous system and the peripheral nervous system [22]. Furthermore, ginseng's long-lasting prowess has been demonstrated as well as its enhanced benefit in a disease state than a healthy state [23-25]. Additionally, a previous study reported the molecular mechanisms and cardiovascular clinical applications of ginseng [19].

Koreans have traditionally used $P$. ginseng roots and root extracts to revitalize the body and mind, increase physical strength, prevent aging, and increase vigor. A new pharmacological concept of the tonic effect of ginseng has arisen [26], resulting in interest and attention by explaining the basic pharmacology of ginseng with adaptogen effects. Ginseng use is common in individuals who have cardiovascular risk factors, such as hypertension, hypercholesterolemia, and oxidative damage. Yet, its' cardiovascular safety and efficacy are unclear. This review summarizes the current knowledge regarding the efficacy of ginseng on the major cardiovascular risk factors of blood pressure, cardiac ischemia, vasomotor activity, lipid profile, and oxidative stress.

\section{EFFICACY OF REGULATING INTRACELLU- LAR ION CHANNELS}

In the heart, calcium ion $\left(\mathrm{Ca}^{2+}\right)$ is crucial for the regulation of contraction and intracellular signaling, which are vital to heart function. $\mathrm{Ca}^{2+}$-activated signaling pathways must function against a background of large, rapid, and tightly regulated changes in intracellular free $\mathrm{Ca}^{2+}$ concentrations during each contraction and relaxation 


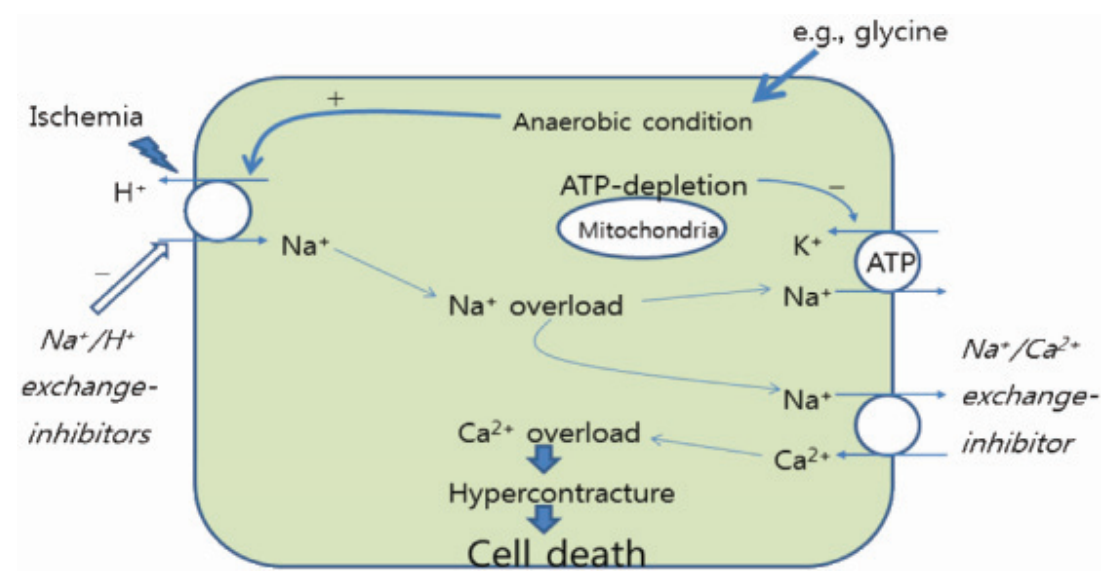

Fig. 2. Role of sodium- and calcium-overload in the pathogenesis of hypercontracture after cardiac ischemia/reperfusion.

cycle (Fig. 2).

Ginsenoside $\mathrm{Rb}_{1}$ inhibits cardiac hypertrophy in a rat model [27]. Ginsenoside Rd reverses basilar hypertrophic remodeling in stroke-prone renovascular hypertensive rats as a new voltage-independent $\mathrm{Ca}^{2+}$ entry blocker [28]. Also, the effect of sugar position in ginsenosides on inhibitory potency of $\mathrm{Na}^{+} / \mathrm{K}^{+}$-ATPase activity has been described [29]. Another study reported that mutations in the Leu427, Asn428, and Leu431 residues attenuate ginsenoside-mediated L-type $\mathrm{Ca}^{2+}$ channel current inhibition [30]. The data indicate that ginsenosides inhibit $\mathrm{Ca}^{2+}$ entry, and so may ameliorate cardiac function.

\section{EFFICACY OF ADJUSTING BLOOD PRESSURE}

Ginseng use was once rumored to increase blood pressure to unhealthy levels. While ginseng can elevate blood pressure, this generally occurs with low blood pressure, which helps restore blood pressure to normal; ginseng also lowers high blood pressure [31]. Biochemical and pharmacological activities of ginseng related to blood pressure control are being clarified with continued research. The vasodilation action of $P$. ginseng improves blood circulation [32]. Korean red ginseng has an antihypertensive effect, which appears to be related to lower rather than higher doses of ginsenosides [33]. In addition, the blood pressure lowering activity of $P$. ginseng is due to promotion of vascular endothelial cell-derived nitric oxide (NO) secretion [32,34]. Furthermore, a mixed aqueous extract of salvia miltiorrhiza and $P$. notoginseng demonstrated anti-hypertensive effects by inhibition of arterial myogenic responses [35]. The collective observations indicate that ginseng normalizes blood pressure and improves blood circulation.

\section{EFFICACY OF IMPROVING MYOCARDIAL PROTECTION}

Ginseng has been used for treatment of heart failure and to protect tissues from damage when an organism is under stress [36]. These attributes come with the added advantage of an absence of harmful side effects. Saponins from $P$. notoginseng protect against doxorubicininduced cardiotoxicity in mice [37]. Total ginsenosides inhibit right ventricular hypertrophy in rats [38] and nitric oxide functions in ginsenoside $\mathrm{Rg}_{1}$-induced protection against left ventricular hypertrophy in rats [39]. Ginsenoside Re suppresses electromechanical alternans in cat and human cardiomyocytes [40] and ginsenoside $\mathrm{Rb}_{1}$ preconditioning protects against myocardial infarction after regional ischemia and reperfusion [41]. Left ventricular hypertrophy in rats is also inhibited by ginsenoside $\mathrm{Rg}_{1}$ [42]. Another study suggested that $P$. ginseng suppresses apoptosis by regulation of Bcl-2 and caspase-3 during hypoxia/reoxygenation in neonatal rat cardiomyocytes [43]. The effects of wild ginseng and astragali radix pharmacopuncture have been compared on the autonomic nervous system and heart rate variability [44]. In addition, ginsenoside $\mathrm{Rg}_{1}$ protects rat cardiomyocyte from hypoxia/reoxygenation oxidative injury via antioxidant and intracellular calcium homeostasis [45]. The protective effects of ginseng total saponin, panaxadiol, and panaxatriol on ischemia/reperfusion injury have been documented in isolated rat heart [46]. The protective role of ginsenoside $\mathrm{Rb}_{1}$ against myocardial ischemia/reperfusion injury in streptozotocin-induced diabetic rats has been reported [47], as has the role of ginseng in reducing adverse post-myocardial remodeling [48]. The results of another study supported the suggestion that ginseng inhibits cardiomyocyte hypertrophy and heart failure via 
Nhe-1 inhibition and attenuation of calcineurin activation [49]. Furthermore, compound K, a metabolite of ginsenosides, bestows nitric oxide-mediated cardiac protection via the Akt/phosphoinositol-3-kinase (PI3K) pathway [50]. Ginseng also protects from cardiac injury by acute myocardial ischemia-reperfusion in rodents through $\mathrm{Gr} /$ Er-activated risk pathway in an endothelial nitric oxide synthase (eNOS)-dependent mechanism [51]. The collective data conclusively indicate that ginseng protects from myocardial damage.

\section{EFFICACY OF REGULATING VASCULAR EN- DOTHELIAL CELLS}

Individuals with peripheral arterial disease typically have atherosclerotic disease affecting several vascular beds, including coronary, cerebral, and renal beds [52]. This may account for both the increased cardiac morbidity and mortality [53]. Scientifically proven pharmacological effects of ginseng on vascular endothelial cells are as follows. Ginsenoside $\mathrm{Rb}_{1}$ has effects on human umbilical vein endothelial cells in vitro [54]. Water extract of Korean red ginseng exhibits angiogenesis by activating the PI3K/Akt-dependent extracellular signalregulated kinase $1 / 2$ and eNOS pathways in human umbilical vein endothelial cells [55]. Ginsenosides also exhibit angiomodulatory and neurological effects [56]. Moreover, ginsensoside Re activates potassium channels of vascular smooth muscle cells through PI3k/Akt and NO pathways [57]. In addition, ginsenoside-Re has nongenomic effects of in endothelial cells via the glucocorticoid receptor [58]. Ginsenoside $\mathrm{Rb}_{1}$ may attenuate capillary morphogenesis by the action of oestrogen receptor beta agonist [59] and induces the signaling pathway of NO production in human aortic endothelial cells [60]. Ginsenoside $\mathrm{Rg}_{1}$ and $\mathrm{Re}$ isolated from $P$. ginseng are stable angiogenic agents [61]. Extracts from $P$. notoginseng and $P$. ginseng fruit enhance vascular endothelial cell proliferation and migration in vitro [62]. Moreover, experiments using fluorescent transgenic mice established the angiogenic effect of ginsenoside $\operatorname{Rg}_{1}$ from $P$. ginseng [63]. The role of this ginsenoside $\mathrm{Rg}_{1}$ in the induction of angiogenesis was also established in another study [64]. The angiogenic effect of saponin extract from P. notoginseng on human umbilical vein endothelial cells in vitro and zebrafish in vivo has been described [65]. The results of another study suggested that $P$. notoginseng reduces atherosclerotic lesions in ApoE-deficient mice and inhibits tumor necrosis factor-alpha-induced endothelial adhesion molecule expression and monocyte adhesion [66].
Ginsenoside $\mathrm{Rg}_{3}$ increases NO production via increases in phosphorylation and expression of eNOS [67]. Compound $\mathrm{K}$ inhibits basic fibroblast growth factor-induced angiogenesis through regulation of p38 mitogen-activated protein kinase and Akt in human umbilical vein endothelial cells [68]. Ginsenoside $\mathrm{Rg}_{1}$ induces angiogenesis via non-genomic crosstalk of glucocorticoid receptor and fibroblast growth factor receptor 1 [69] and mediates the microenvironment-dependent endothelial differentiation of human mesenchymal stem cells in vitro [70]. Furthermore, ginsenoside $R b_{1}$ protects against endothelial cell damage and stimulates ghrelin expression induced by hyperhomocysteine [71]. These collective observations suggest that ginseng saponin protects vascular endothelial cells via cellular signaling pathway.

\section{EFFICACY OF REGULATING VASOMOTOR FUNCTIONS}

The cardiovascular effects of ginseng and individual ginsenosides have been amply reviewed. Many reports describe transient vasodilator actions, in some cases followed by vasoconstriction and an increase in blood pressure. The endothelium contributes to the control of vascular smooth muscle tone by production and release of $\mathrm{NO}$, which accounts for the biological activity of the endothelium-derived relaxing factor [72-74]. Ginsenosides have been shown to stimulate NO production in several systems. One study examined purified ginsenoside $\mathrm{Rb}_{1^{-}}$ induced NO production in human aortic endothelial cells [60]. Another study reported that this ginsenoside increased the phosphorylation of glucocorticoid receptor, $\mathrm{PI} 3 \mathrm{~K}, \mathrm{Akt} /$ protein kinase $\mathrm{B}$, and eNOS, leading to increased NO production in human umbilical vein endothelial cells [75]. Other studies investigated the relaxation mechanism of ginsenoside $\mathrm{Rg}_{3}$ using isolated canine corpus cavernosum [76] and demonstrated the effects of Korean red ginseng and its isolated ginsenosides and polysaccharides on arterial stiffness in healthy individuals [77]. Studies with ginsenoside $\mathrm{Rg}_{3}$ reported induced vascular smooth muscle dysfunction and remodeling [78] and the inhibition of angiotensin II-induced vascular smooth muscle cell proliferation [79]. The effects of total saponins of $P$. notoginseng on aortic intimal hyperplasia and the expression of cell cycle protein and extracellular matrix in rats has been reported [80]. Finally, the benefit of Korean red ginseng on arterial stiffness in subjects with hypertension was reported [81]. Together, these results indicate that ginseng and ginsenosides ameliorate vasomotor function. 


\section{EFFICACY OF IMPROVING BLOOD CIRCU- LATION}

Reports have documented ginseng's inhibitory effects on platelet aggregation [82] and endotoxin-induced disseminated intravascular coagulation [83], which has led to the use of ginseng, particularly Korean red ginseng, as an anti-thrombotic and fibrinolytic agent [84]. The role of ginsenoside $\mathrm{Rg}_{3}$ in the inhibition of platelet aggregation has been described [85]. The role of ginsenosides in protecting human erythrocytes against hemin-induced hemolysis has been described [86]. Screening of antiplatelet aggregation agents from $P$. notoginseng can be done using human platelet extraction [87]. P. notoginseng saponins improve the post-treatment effects on lipopolysaccharide-induced microcirculatory disturbance in rat mesentery [88]. Anti-platelet and anti-coagulant effects of $P$. notoginseng were described in a comparison of raw and steamed $P$. notoginseng with $P$. ginseng and $P$. quinquefolium [89]. The platelet anti-aggregating activity of ginsenosides isolated from ginseng has been reported [90,91]. Another study documented the interaction between warfarin and Korean red ginseng in patients with cardiac valve replacement [92]. Total ginsenosides increase coronary perfusion flow in isolated rat hearts by activating PI3K/Akt-eNOS signaling [93]. Red ginseng extract improves coronary flow reserve and increases absolute numbers of various circulating angiogenic cells in patients with acute myocardial infarction [94]. Overall, these results suggest that ginseng may improve blood circulation by inhibiting platelet aggregation and coagulation activity.

\section{EFFICACY OF ADJUSTING BLOOD LIPID PRO- FILE}

Metabolic syndrome - defined as a cluster of three of insulin resistance and glucose intolerance, abdominal obesity, hypertension, low high density lipoprotein cholesterol, and hypertriglyceridemia - has become a global epidemic. The prevalence of metabolic syndrome in adults has been increasing rapidly in the past decades in most western countries, and the situation is even worse in people over 60-years-of-age [95]. Given the fact that people who have metabolic syndrome are susceptible to atherosclerotic CDV [96], effective and feasible therapeutic strategies are urgently needed for the treatment of complications of metabolic syndrome. In recent years, more attention has been paid to bioactive components from P. ginseng. Particularly, it was reported that $P$. gin- seng saponin reduces weight gain in mice [97]. Bifidus fermentation was shown to increase the hypolipidemic and hypoglycemic effects of red ginseng [98]. Korean red ginseng attenuates hypercholesterolemia-enhanced platelet aggregation by suppressing diacylglycerol liberation in rabbits fed a diet high in cholesterol [99]. $P$. notoginseng saponins attenuate atherosclerosis by regulating the lipid profile and have an anti-inflammatory action in rats [100] and atherosclerosis is inhibited by total P. notoginsenosides in apolipoprotein E-knockout mice [101]. Also, cholesterol ester can be decreased by $P$. notoginseng saponins by the up-regulation of the ATPbinding cassette transporter A1 in foam cells [102]. The anti-hyperlipidemic effects of acidic polysaccharide from Korean red ginseng were reported [103]. P. notoginseng saponins attenuate atherogenesis in rabbits [104] and radix notoginseng has hypolipidemic and anti-oxidant activities in rats fed a high fat diet [105]. Ginsenoside-Rd prevents atherosclerosis in ApoE-knockout mice [106]. Overall, these results suggest that $P$. ginseng improves the lipid profile.

\section{OXIDATION AND GINSENG}

The production of reactive oxygen species (ROS) from various cellular metabolic processes caused by the restoration of coronary flow after cardiac ischemia is thought to contribute to myocardial damage [107-109]. ROS cause non-specific damage to lipids, proteins and DNA, leading to an alteration or loss of the cellular function. The abrupt rise in ROS as a result of the reoxygenation of ischemic or hypoxic cardiac muscle has been associated with a partially irreversible inhibition of mitochondrial respiration [110]. Alterations in generation and/or use of energy are thought to be important contributing factors to the observed dysfunction caused by ischemia reperfusion injury [111]. It is recognized that a free radical that is produced in excess of what is reasonably sufficient in the body may induce CVD. Therefore, extensive studies have been conducted on the cardioprotective effects of ginseng against free radical damage.

\section{EFFICACY OF ANTI-OXIDANT ACTIVITY}

The scientifically-proven pharmacological effects of ginseng against oxidative damage are as follows. Ginseng and ginsenosides have an anti-oxidant effect that is manifest as an inhibited increase in harmful free radical formation and lipid peroxidation [112-116]. Ginsenosides $\mathrm{Rg}_{2}$ and $\mathrm{Rh}_{1}$ protect from oxidation-induced impairment 
of erythrocyte membrane properties [117]. P. ginseng polysaccharide is effective in the regulation of energy metabolism and protection of mitochondria [118]. Studies with American ginseng reported the mediation of anti-oxidant actions via Nrf2 in cardiomyocytes [119] and ginseng-related increased activity of the antioxidant enzymes, superoxide dismutase and glutathione peroxidase in rats [120]. Another in vivo study reported that ginsenosides protected against myocardial reperfusion damage with a concomitant increase in 6-keto-prostaglandin F1a and a decrease in lipid peroxidation, and also protected rabbit pulmonary and aortic endothelium against electrolysis-induced free radical damage [121]. Ginsenosides also protected rabbit pulmonary endothelium from injury induced by a variant of ROS [15]. Also, it was reported that ginseng prevented manifestations of ROS injury by promoting the release of NO. Endothelial dysfunction induced by homocysteine and human immunodeficiency virus protease inhibitors can be effectively blocked by $\mathrm{Rb}_{1}$ and other ginsenosides $[122,123]$, confirming the role of ginsenoside $\mathrm{Rb}_{1}$ and other ginsenosides in blocking ROS production. In addition, ginsenoside Re possesses anti-oxidant effects in cardiomyocytes [124]. Ginsenosides exert their anti-oxidant ability by increasing internal antioxidant enzymes and acting as a freeradical scavenger [125-127]. Moreover, individual ginsenosides behave as an anti-oxidant if glucose is attached to the 20-position of the triterpene dammarane, such as $\mathrm{Re}, \mathrm{Rd}$, and $\mathrm{R}_{1}$, but as a pro-oxidant if there are no sugar moieties attached to the 20-position of the ginsenoside such as $\mathrm{Rg}_{3}, \mathrm{Rh}_{2}$, and $\mathrm{Rg}_{2}$ [128]. If a glucose is attached to the 6-position instead of 20-position sugar moieties, however, the ginsenoside still act as an anti-oxidant (e.g., $\mathrm{Rh}_{1}$ ) [128]. Overall, these results suggest that ginseng may inhibit oxidative damage due to prevention of ROS generation.

\section{CONCLUSION}

Ginseng is a traditional herbal medicine whose history stretches back millennia. The basis of ginseng's prowess is its' many active constituent ginsenosides. Ginseng has extensive pharmacological activies and specific mechanisms of action. Ginsenosides can inhibit ROS production, stimulate NO production, increase blood circulation, ameliorate vasomotor tone, and adjust lipid profile. Additionally, many studies indicate that ginsenosides have a multitude of activities in both physiological and/or pathologic conditions concerning with CVD. How these effects relate to the ginsenoside structures are still not yet fully understood. Future cardiovascular studies involving each ginsenoside should include the mechanisms of action in more detail, with emphasis on specificity, structure and function relationship, detailed pharmacokinetics and toxicity researches, and therapeutic studies in both animal and human models.

\section{REFERENCES}

1. Kritharides L, Brown A, Brieger D, Ridell T, Zeitz C, Jeremy R, Tonkin A, Walsh W, White H. Overview and determinants of cardiovascular disease in indigenous populations. Heart Lung Circ 2010;19:337-343.

2. Pratt C. Alternative prevention and treatment of cardiovascular disease, part 2. Prim Care 2010;37:339-366.

3. Ulrich S, Hingorani AD, Martin J, Vallance P. Lifetime risk of developing coronary heart disease. Lancet 1999;353:925.

4. Tunstall-Pedoe H, Vanuzzo D, Hobbs M, Mahonen M, Cepaitis Z, Kuulasmaa K, Keil U. Estimation of contribution of changes in coronary care to improving survival, event rates, and coronary heart disease mortality across the WHO MONICA Project populations. Lancet 2000;355:688-700.

5. Toth PP. Making a case for quantitative assessment of cardiovascular risk. J Clin Lipidol 2007;1:234-241.

6. Libby P. What have we learned about the biology of atherosclerosis? The role of inflammation. Am J Cardiol 2001;88(7B):3J-6J.

7. Libby P. Act local, act global: inflammation and the multiplicity of "vulnerable" coronary plaques. J Am Coll Cardiol 2005;45:1600-1602.

8. Davies MJ, Gordon JL, Gearing AJ, Pigott R, Woolf N, Katz D, Kyriakopoulos A. The expression of the adhesion molecules ICAM-1, VCAM-1, PECAM, and E-selectin in human atherosclerosis. J Pathol 1993;171:223-229.

9. Tabas I. Consequences and therapeutic implications of macrophage apoptosis in atherosclerosis: the importance of lesion stage and phagocytic efficiency. Arterioscler Thromb Vasc Biol 2005;25:2255-2264.

10. Tabas I, Williams KJ, Boren J. Subendothelial lipoprotein retention as the initiating process in atherosclerosis: update and therapeutic implications. Circulation 2007;116:1832-1844.

11. Schechter CB. Longevity and cardiovascular disease: context and overview. Arch Intern Med 2007;167:428-429.

12. Boudina S, Laclau MN, Tariosse L, Daret D, Gouverneur G, Bonoron-Adele S, Saks VA, Dos Santos P. Alteration of mitochondrial function in a model of chronic ischemia in vivo in rat heart. Am J Physiol Heart Circ Physiol 
2002;282:H821-H831.

13. Shibata S, Fujita M, Itokawa H, Tanaka O, Ishii T. Studies on the constituents of Japanese and Chinese crude drugs. XI. Panaxadiol, a sapogenin of ginseng roots. Chem Pharm Bull (Tokyo) 1963;11:759-761.

14. Shibata S, Tanaka O, Soma K, Ando T, Iida Y, Nakamura H. Studies on saponins and sapogenins of ginseng. The structure of panaxatriol. Tetrahedron Lett 1965;42:207213.

15. Gillis CN. Panax ginseng pharmacology: a nitric oxide link? Biochem Pharmacol 1997;54:1-8.

16. Buettner C, Yeh GY, Phillips RS, Mittleman MA, Kaptchuk TJ. Systematic review of the effects of ginseng on cardiovascular risk factors. Ann Pharmacother 2006;40:83-95.

17. Hofseth LJ, Wargovich MJ. Inflammation, cancer, and targets of ginseng. J Nutr 2007;137(1 Suppl):183S-185S.

18. Attele AS, Wu JA, Yuan CS. Ginseng pharmacology: multiple constituents and multiple actions. Biochem Pharmacol 1999;58:1685-1693.

19. Zhou W, Chai H, Lin PH, Lumsden AB, Yao Q, Chen CJ. Molecular mechanisms and clinical applications of ginseng root for cardiovascular disease. Med Sci Monit 2004;10:RA187- RA192.

20. Cheng Y, Shen LH, Zhang JT. Anti-amnestic and anti-aging effects of ginsenoside $\mathrm{Rg}_{1}$ and $\mathrm{Rb}_{1}$ and its mechanism of action. Acta Pharmacol Sin 2005;26:143-149.

21. Fuzzati N. Analysis methods of ginsenosides. J Chromatogr B Analyt Technol Biomed Life Sci 2004;812:119133.

22. Nah SY, Kim DH, Rhim H. Ginsenosides: are any of them candidates for drugs acting on the central nervous system? CNS Drug Rev 2007;13:381-404.

23. Brekhman II, Dardymov IV. New substances of plant origin which increase nonspecific resistance. Annu Rev Pharmacol 1969;9:419-30.

24. Bittles AH, Fulder SJ, Grant EC, Nicholls MR. The effect of ginseng on lifespan and stress responses in mice. Gerontology 1979;25:125-131.

25. Zhou DH. Preventive geriatrics: an overview from traditional Chinese medicine. Am J Chin Med 1982;10:32-39.

26. Brekhman II. Panax ginseng. Leningrad: Gosudaarst Isdat et Med Lit, 1957.

27. Jiang QS, Huang XN, Dai ZK, Yang GZ, Zhou QX, Shi $\mathrm{JS}, \mathrm{Wu} \mathrm{Q}$. Inhibitory effect of ginsenoside $\mathrm{Rb}_{1}$ on cardiac hypertrophy induced by monocrotaline in rat. J Ethnopharmacol 2007;111:567-572.

28. Cai BX, Li XY, Chen JH, Tang YB, Wang GL, Zhou JG, Qui QY, Guan YY. Ginsenoside-Rd, a new voltage-independent $\mathrm{Ca} 2+$ entry blocker, reverses basilar hypertrophic remodeling in stroke-prone renovascular hypertensive rats. Eur J Pharmacol 2009;606:142-149.

29. Chen RJ, Chung TY, Li FY, Lin NH, Tzen JT. Effect of sugar positions in ginsenosides and their inhibitory potency on $\mathrm{Na}+/ \mathrm{K}+$-ATPase activity. Acta Pharmacol Sin 2009;30:61-69.

30. Choi SH, Lee JH, Pyo MK, Lee BH, Shin TJ, Hwang $\mathrm{SH}$, Kim BR, Lee SM, Oh JW, Kim HC et al. Mutations Leu427, Asn428, and Leu431 residues within transmembrane domain-I-segment 6 attenuate ginsenoside-mediated L-type $\mathrm{Ca}(2+)$ channel current inhibitions. Biol Pharm Bull 2009;32:1224-1230.

31. Jeon BH, Kim CS, Park KS, Lee JW, Park JB, Kim KJ, Kim SH, Chang SJ, Nam KY. Effect of Korea red ginseng on the blood pressure in conscious hypertensive rats. Gen Pharmacol 2000;35:135-141.

32. Kang SY, Schini-Kerth VB, Kim ND. Ginsenosides of the protopanaxatriol group cause endothelium-dependent relaxation in the rat aorta. Life Sci 1995;56:1577-1586.

33. Vuksan V, Stavro M, Woo M, Leiter LA, Sung MK, Sievenpiper JL. Korean red ginseng (Panax ginseng) can lower blood pressure in individuals with hypertension: a randomized controlled trial. Proceedings of the 9th International Ginseng Symposium; 2006 Sep 25-28; Geumsan, Korea. Seoul: Korean Society of Ginseng, 2006.

34. Kim ND, Kang SY, Schini VB. Ginsenosides evoke endothelium-dependent vascular relaxation in rat aorta. Gen Pharmacol 1994;25:1071-1077.

35. Baek EB, Yoo HY, Park SJ, Chung YS, Hong EK, Kim SJ. Inhibition of arterial myogenic responses by a mixed aqueous extract of salvia miltiorrhiza and Panax notoginseng (PASEL) showing antihypertensive effects. Korean J Physiol Pharmacol 2009;13:287-293.

36. Wagner HN, Liu X. The international textbook of cardiology. New York: Pergamon Press, 1987.

37. Liu L, Shi R, Shi Q, Cheng Y, Huo Y. Protective effect of saponins from Panax notoginseng against doxorubicininduced cardiotoxicity in mice. Planta Med 2008;74:203209.

38. Qin N, Gong QH, Wei LW, Wu Q, Huang XN. Total ginsenosides inhibit the right ventricular hypertrophy induced by monocrotaline in rats. Biol Pharm Bull 2008;31:15301535.

39. Deng J, Wang YW, Chen WM, Wu Q, Huang XN. Role of nitric oxide in ginsenoside $\mathrm{Rg}(1)$-induced protection against left ventricular hypertrophy produced by abdominal aorta coarctation in rats. Biol Pharm Bull 2010; 33:631-635.

40. Wang YG, Zima AV, Ji X, Pabbidi R, Blatter LA, Lipsius SL. Ginsenoside Re suppresses electromechanical alter- 
nans in cat and human cardiomyocytes. Am J Physiol Heart Circ Physiol 2008;295:H851-H859.

41. Wang Z, Li M, Wu WK, Tan HM, Geng DF. Ginsenoside $\mathrm{Rb}_{1}$ preconditioning protects against myocardial infarction after regional ischemia and reperfusion by activation of phosphatidylinositol-3-kinase signal transduction. Cardiovasc Drugs Ther 2008;22:443-452.

42. Deng J, Lv XT, Wu Q, Huang XN. Ginsenoside Rg(1) inhibits rat left ventricular hypertrophy induced by abdominal aorta coarctation: involvement of calcineurin and mitogen-activated protein kinase signalings. Eur J Pharmacol 2009;608:42-47.

43. Wang YL, Wang CY, Zhang BJ, Zhang ZZ. Shenfu injection suppresses apoptosis by regulation of Bcl-2 and caspase-3 during hypoxia/reoxygenation in neonatal rat cardiomyocytes in vitro. Mol Biol Rep 2009;36:365-370.

44. Yook T, Yu J, Lee H, Song B, Kim L, Roh J, Shin J, Lim S. Comparing the effects of distilled rehmannia glutinosa, wild ginseng and astragali radix pharmacopuncture with heart rate variability (HRV): a randomized, sham-controlled and double-blind clinical trial. J Acupunct Meridian Stud 2009;2:239-247.

45. Zhu D, Wu L, Li CR, Wang XW, Ma YJ, Zhong ZY, Zhao HB, Cui J, Xun SF, Huang XL et al. Ginsenoside $\mathrm{Rg}_{1}$ protects rat cardiomyocyte from hypoxia/reoxygenation oxidative injury via antioxidant and intracellular calcium homeostasis. J Cell Biochem 2009; 108:117-124.

46. Kim TH, Lee SM. The effects of ginseng total saponin, panaxadiol and panaxatriol on ischemia/reperfusion injury in isolated rat heart. Food Chem Toxicol 2010;48:15161520.

47. Wu Y, Xia ZY, Dou J, Zhang L, Xu JJ, Zhao B, Lei S, Liu $\mathrm{HM}$. Protective effect of ginsenoside $\mathrm{Rb}_{1}$ against myocardial ischemia/reperfusion injury in streptozotocin-induced diabetic rats. Mol Biol Rep 2011;38:4327-4335.

48. Bodiga S, Wang W, Oudit GY. Use of ginseng to reduce post-myocardial adverse myocardial remodeling: applying scientific principles to the use of herbal therapies. J Mol Med (Berl) 2011;89:317-320.

49. Guo J, Gan XT, Haist JV, Rajapurohitam V, Zeidan A, Faruq NS, Karmazyn M. Ginseng inhibits cardiomyocyte hypertrophy and heart failure via NHE-1 inhibition and attenuation of calcineurin activation. Circ Heart Fail 2011;4:79-88.

50. Tsutsumi YM, Tsutsumi R, Mawatari K, Nakaya Y, Kinoshita M, Tanaka K, Oshita S. Compound K, a metabolite of ginsenosides, induces cardiac protection mediated nitric oxide via Akt/PI3K pathway. Life Sci 2011;88:725729.

51. Zhou H, Hou SZ, Luo P, Zeng B, Wang JR, Wong YF,
Jiang ZH, Liu L. Ginseng protects rodent hearts from acute myocardial ischemia-reperfusion injury through GR/ER-activated RISK pathway in an endothelial NOSdependent mechanism. J Ethnopharmacol 2011;135:287298.

52. Criqui MH, Langer RD, Fronek A, Feigelson HS, Klauber MR, McCann TJ, Browner D. Mortality over a period of 10 years in patients with peripheral arterial disease. $\mathrm{N}$ Engl J Med 1992;326:381-386.

53. Schouten O, Poldermans D. Cardiac risk in non-cardiac surgery. Br J Surg 2007;94:1185-1186.

54. He F, Guo R, Wu SL, Sun M, Li M. Protective effects of ginsenoside $R b_{1}$ on human umbilical vein endothelial cells in vitro. J Cardiovasc Pharmacol 2007;50:314-320.

55. Kim YM, Namkoong S, Yun YG, Hong HD, Lee YC, Ha KS, Lee H, Kwon HJ, Kwon YG, Kim YM. Water extract of Korean red ginseng stimulates angiogenesis by activating the PI3K/Akt-dependent ERK1/2 and eNOS pathways in human umbilical vein endothelial cells. Biol Pharm Bull 2007;30:1674-1679.

56. Leung KW, Yung KK, Mak NK, Yue PY, Luo HB, Cheng YK, Fan TP, Yeung HW, Ng TB, Wong RN. Angiomodulatory and neurological effects of ginsenosides. Curr Med Chem 2007;14:1371-1380.

57. Nakaya Y, Mawatari K, Takahashi A, Harada N, Hata A, Yasui S. The phytoestrogen ginsensoside Re activates potassium channels of vascular smooth muscle cells through PI3K/Akt and nitric oxide pathways. J Med Invest 2007;54:381-384.

58. Leung KW, Leung FP, Huang Y, Mak NK, Wong RN. Non-genomic effects of ginsenoside-Re in endothelial cells via glucocorticoid receptor. FEBS Lett 2007;581: 2423-2428.

59. Papapetropoulos A. A ginseng-derived oestrogen receptor beta (ERbeta) agonist, $\mathrm{Rb}_{1}$ ginsenoside, attenuates capillary morphogenesis. Br J Pharmacol 2007;152:172-174.

60. Yu J, Eto M, Akishita M, Kaneko A, Ouchi Y, Okabe T. Signaling pathway of nitric oxide production induced by ginsenoside $R b_{1}$ in human aortic endothelial cells: a possible involvement of androgen receptor. Biochem Biophys Res Commun 2007;353:764-769.

61. Yu LC, Chen SC, Chang WC, Huang YC, Lin KM, Lai $\mathrm{PH}$, Sung HW. Stability of angiogenic agents, ginsenoside $\mathrm{Rg}_{1}$ and $\mathrm{Re}$, isolated from Panax ginseng: in vitro and in vivo studies. Int J Pharm 2007;328:168-176.

62. Lei Y, Gao Q, Chen KJ. Effects of extracts from Panax notoginseng and Panax ginseng fruit on vascular endothelial cell proliferation and migration in vitro. Chin J Integr Med 2008; 14:37-41.

63. Lin KM, Hsu CH, Rajasekaran S. Angiogenic evaluation 
of ginsenoside $\mathrm{Rg}_{1}$ from Panax ginseng in fluorescent transgenic mice. Vascul Pharmacol 2008;49:37-43.

64. Chan LS, Yue PY, Mak NK, Wong RN. Role of microRNA-214 in ginsenoside- $\mathrm{Rg}_{1}$-induced angiogenesis. Eur J Pharm Sci 2009;38:370-377.

65. Hong SJ, Wan JB, Zhang Y, Hu G, Lin HC, Seto SW, Kwan YW, Lin ZX, Wang YT, Lee SM. Angiogenic effect of saponin extract from Panax notoginseng on HUVECs in vitro and zebrafish in vivo. Phytother Res 2009;23:677686.

66. Wan JB, Lee SM, Wang JD, Wang N, He CW, Wang YT, Kang JX. Panax notoginseng reduces atherosclerotic lesions in ApoE-deficient mice and inhibits TNF-alphainduced endothelial adhesion molecule expression and monocyte adhesion. J Agric Food Chem 2009;57:66926697.

67. Hien TT, Kim ND, Pokharel YR, Oh SJ, Lee MY, Kang $\mathrm{KW}$. Ginsenoside $\mathrm{Rg}_{3}$ increases nitric oxide production via increases in phosphorylation and expression of endothelial nitric oxide synthase: essential roles of estrogen receptor-dependent PI3-kinase and AMP-activated protein kinase. Toxicol Appl Pharmacol 2010;246:171-183.

68. Jeong A, Lee HJ, Jeong SJ, Lee HJ, Lee EO, Bae H, Kim $\mathrm{SH}$. Compound $\mathrm{K}$ inhibits basic fibroblast growth factorinduced angiogenesis via regulation of p38 mitogen activated protein kinase and AKT in human umbilical vein endothelial cells. Biol Pharm Bull 2010;33:945-950.

69. Cheung LW, Leung KW, Wong CK, Wong RN, Wong AS. Ginsenoside- $\mathrm{Rg}_{1}$ induces angiogenesis via non-genomic crosstalk of glucocorticoid receptor and fibroblast growth factor receptor-1. Cardiovasc Res 2011;89:419-425.

70. He W, Wu WK, Wu YL, Yang XH, Lin QX, Yu WH. Ginsenoside- $\mathrm{Rg}_{1}$ mediates microenvironment-dependent endothelial differentiation of human mesenchymal stem cells in vitro. J Asian Nat Prod Res 2011;13:1-11.

71. Xu Z, Lan T, Wu W, Wu Y. The effects of ginsenoside $R b_{1}$ on endothelial damage and ghrelin expression induced by hyperhomocysteine. J Vasc Surg 2011;53:156-164.

72. Furchgott RF, Vanhoutte PM. Endothelium-derived relaxing and contracting factors. FASEB J 1989;3:2007-2018.

73. Ignarro LJ. Biological actions and properties of endothelium-derived nitric oxide formed and released from artery and vein. Circ Res 1989;65:1-21.

74. Moncada S, Palmer RM, Higgs EA. Nitric oxide: physiology, pathophysiology, and pharmacology. Pharmacol Rev 1991;43:109-142.

75. Leung KW, Cheng YK, Mak NK, Chan KK, Fan TP, Wong RN. Signaling pathway of ginsenoside-Rg1 leading to nitric oxide production in endothelial cells. FEBS Lett 2006;580:3211-3216.
76. Kang YJ, Sohn JT, Chang KC. Relaxation of canine corporal smooth muscle relaxation by ginsenoside sapo$\operatorname{nin} \mathrm{Rg}_{3}$ is independent from eNOS activation. Life Sci 2005; $77: 74-84$

77. Jovanovski E, Jenkins A, Dias AG, Peeva V, Sievenpiper J, Arnason JT, Rahelic D, Josse RG, Vuksan V. Effects of Korean red ginseng (Panax ginseng C.A. Mayer) and its isolated ginsenosides and polysaccharides on arterial stiffness in healthy individuals. Am J Hypertens 2010;23:469472.

78. Lee JY, Lim KM, Kim SY, Bae ON, Noh JY, Chung SM, Kim K, Shin YS, Lee MY, Chung JH. Vascular smooth muscle dysfunction and remodeling induced by ginsenoside $\mathrm{Rg}_{3}$, a bioactive component of ginseng. Toxicol Sci 2010;117:505-514.

79. Wang T, Yu XF, Qu SC, Xu HL, Sui DY. Ginsenoside $\mathrm{Rb}_{3}$ inhibits angiotensin II-induced vascular smooth muscle cells proliferation. Basic Clin Pharmacol Toxicol 2010;107:685-689.

80. Wu L, Zhang W, Tang YH, Li H, Chen BY, Zhang GM, Deng CQ. Effect of total saponins of "Panax notoginseng root" on aortic intimal hyperplasia and the expressions of cell cycle protein and extracellular matrix in rats. Phytomedicine 2010;17:233-240.

81. Rhee MY, Kim YS, Bae JH, Nah DY, Kim YK, Lee MM, Kim HY. Effect of Korean red ginseng on arterial stiffness in subjects with hypertension. J Altern Complement Med 2011; 17:45-49.

82. Tamura Y. Effects of Korean red ginseng on eicosanoid biosynthesis in platelets and vascular smooth muscle cells. Proceedings of the 6th International Ginseng Symposium; 1993 Sep 6-9; Seoul, Korea. Daejeon: Korea Ginseng \& Tobacco Research Institute, 1993.

83. Harima S, Matsuda H, Kubo M. Study of various rhubarbs regarding the cathartic effect and endotoxin-induced disseminated intravascular coagulation. Biol Pharm Bull 1994;17:1522-1525.

84. Jin YR, Yu JY, Lee JJ, You SH, Chung JH, Noh JY, Im JH, Han XH, Kim TJ, Shin KS et al. Antithrombotic and antiplatelet activities of Korean red ginseng extract. Basic Clin Pharmacol Toxicol 2007;100:170-175.

85. Lee WM, Kim SD, Park MH, Cho JY, Park HJ, Seo GS, Rhee MH. Inhibitory mechanisms of dihydroginsenoside $\mathrm{Rg}_{3}$ in platelet aggregation: critical roles of ERK2 and cAMP. J Pharm Pharmacol 2008;60:1531-1536.

86. Li GX, Liu ZQ. The protective effects of ginsenosides on human erythrocytes against hemin-induced hemolysis. Food Chem Toxicol 2008;46:886-892.

87. Wang J, Huang ZG, Cao H, Wang YT, Hui P, Hoo C, Li SP. Screening of anti-platelet aggregation agents from 
Panax notoginseng using human platelet extraction and HPLC-DAD-ESI-MS/MS. J Sep Sci 2008;31:1173-1180.

88. Yang JY, Sun K, Wang CS, Guo J, Xue X, Liu YY, Zheng J, Fan JY, Liao FL, Han JY. Improving effect of posttreatment with Panax notoginseng saponins on lipopolysaccharide-induced microcirculatory disturbance in rat mesentery. Clin Hemorheol Microcirc 2008;40:119-131.

89. Lau AJ, Toh DF, Chua TK, Pang YK, Woo SO, Koh HL. Antiplatelet and anticoagulant effects of Panax notoginseng: comparison of raw and steamed Panax notoginseng with Panax ginseng and Panax quinquefolium. J Ethnopharmacol 2009;125:380-386.

90. Lee JG, Lee YY, Kim SY, Pyo JS, Yun-Choi HS, Park JH. Platelet antiaggregating activity of ginsenosides isolated from processed ginseng. Pharmazie 2009;64:602-604.

91. Lee JG, Lee YY, Wu B, Kim SY, Lee YJ, Yun-Choi HS, Park JH. Inhibitory activity of ginsenosides isolated from processed ginseng on platelet aggregation. Pharmazie 2010;65:520-522.

92. Lee YH, Lee BK, Choi YJ, Yoon IK, Chang BC, Gwak HS. Interaction between warfarin and Korean red ginseng in patients with cardiac valve replacement. Int J Cardiol 2010;145:275-276.

93. Yi XQ, Li T, Wang JR, Wong VK, Luo P, Wong IY, Jiang $\mathrm{ZH}$, Liu L, Zhou H. Total ginsenosides increase coronary perfusion flow in isolated rat hearts through activation of PI3K/Akt-eNOS signaling. Phytomedicine 2010;17:10061015.

94. Ahn CM, Hong SJ, Choi SC, Park JH, Kim JS, Lim DS. Red ginseng extract improves coronary flow reserve and increases absolute numbers of various circulating angiogenic cells in patients with first ST-segment elevation acute myocardial infarction. Phytother Res 2011;25:239249.

95. Ford ES, Giles WH, Dietz WH. Prevalence of the metabolic syndrome among US adults: findings from the third National Health and Nutrition Examination Survey. JAMA 2002;287:356-359.

96. Lehmann JM, Kliewer SA, Moore LB, Smith-Oliver TA, Oliver BB, Su JL, Sundseth SS, Winegar DA, Blanchard $\mathrm{DE}$, Spencer TA et al. Activation of the nuclear receptor LXR by oxysterols defines a new hormone response pathway. J Biol Chem 1997;272:3137-3140.

97. Karu N, Reifen R, Kerem Z. Weight gain reduction in mice fed Panax ginseng saponin, a pancreatic lipase inhibitor. J Agric Food Chem 2007;55:2824-2828.

98. Trinh HT, Han SJ, Kim SW, Lee YC, Kim DH. Bifidus fermentation increases hypolipidemic and hypoglycemic effects of red ginseng. J Microbiol Biotechnol 2007; 17:1127-1133.
99. Hwang SY, Son DJ, Kim IW, Kim DM, Sohn SH, Lee JJ, Kim SK. Korean red ginseng attenuates hypercholesterolemia-enhanced platelet aggregation through suppression of diacylglycerol liberation in high-cholesterol-diet-fed rabbits. Phytother Res 2008;22:778-783.

100. Zhang YG, Zhang HG, Zhang GY, Fan JS, Li XH, Liu YH, Li SH, Lian XM, Tang Z. Panax notoginseng saponins attenuate atherosclerosis in rats by regulating the blood lipid profile and an anti-inflammatory action. Clin Exp Pharmacol Physiol 2008;35:1238-1244.

101. Liu G, Wang B, Zhang J, Jiang H, Liu F. Total panax notoginsenosides prevent atherosclerosis in apolipoprotein E-knockout mice: role of downregulation of CD40 and MMP-9 expression. J Ethnopharmacol 2009;126:350354.

102. Jia Y, Li ZY, Zhang HG, Li HB, Liu Y, Li XH. Panax notoginseng saponins decrease cholesterol ester via upregulating ATP-binding cassette transporter A1 in foam cells. J Ethnopharmacol 2010;132:297-302.

103. Kwak YS, Kyung JS, Kim JS, Cho JY, Rhee MH. Anti-hyperlipidemic effects of red ginseng acidic polysaccharide from Korean red ginseng. Biol Pharm Bull 2010;33:468-472.

104. Liu Y, Zhang HG, Jia Y, Li XH. Panax notoginseng saponins attenuate atherogenesis accelerated by zymosan in rabbits. Biol Pharm Bull 2010;33:1324-1330.

105. Xia W, Sun C, Zhao Y, Wu L. Hypolipidemic and antioxidant activities of sanchi (radix notoginseng) in rats fed with a high fat diet. Phytomedicine 2011;18:516-520.

106. Li J, Xie ZZ, Tang YB, Zhou JG, Guan YY. Ginsenoside-Rd, a purified component from Panax notoginseng saponins, prevents atherosclerosis in apoE knockout mice. Eur J Pharmacol 2011;652:104-110.

107. Bolli R. Superoxide dismutase 10 years later: a drug in search of a use. J Am Coll Cardiol 1991;18:231-233.

108. Gross GJ, Farber NE, Hardman HF, Warltier DC. Beneficial actions of superoxide dismutase and catalase in stunned myocardium of dogs. Am J Physiol 1986;250(3 Pt 2):H372- H377.

109. Zweier JL, Flaherty JT, Weisfeldt ML. Direct measurement of free radical generation following reperfusion of ischemic myocardium. Proc Natl Acad Sci U S A 1987;84:1404-1407.

110. Xie YW, Shen W, Zhao G, Xu X, Wolin MS, Hintze TH. Role of endothelium-derived nitric oxide in the modulation of canine myocardial mitochondrial respiration in vitro. Implications for the development of heart failure. Circ Res 1996;79:381-387.

111. Taniguchi M, Wilson C, Hunter CA, Pehowich DJ, Clanachan AS, Lopaschuk GD. Dichloroacetate improves 
cardiac efficiency after ischemia independent of changes in mitochondrial proton leak. Am J Physiol Heart Circ Physiol 2001;280:H1762- H1769.

112. Abdel-Wahhab MA, Ahmed HH. Protective effect of Korean Panax ginseng against chromium VI toxicity and free radicals generation in rats. J Ginseng Res 2004;28:1117.

113. Chung YH, Kim KW, Oura H. Effects of ginsenoside $\mathrm{Rb}_{2}$ on the anti-oxidants in senescence-accelerated mice (SAM-R/1). Proceedings of the 6th International Ginseng Symposium; 1993 Sep 6-9; Seoul, Korea. Daejeon: Korea Ginseng \& Tobacco Research Institute, 1993.

114. Chang HM; Chinese University of Hong Kong; Chinese Medicinal Research Centre. Advances in Chinese medicinal materials research. Philadelphia: World Scientific, 1985.

115. Kim H, Chen X, Gillis CN. Ginsenosides protect pulmonary vascular endothelium against free radical-induced injury. Biochem Biophys Res Commun 1992;189:670676.

116. Kim YK, Guo Q, Packer L. Free radical scavenging activity of red ginseng aqueous extracts. Toxicology 2002;172:149-156.

117. Samukawa K, Suzuki Y, Ohkubo N, Aoto M, Sakanaka M, Mitsuda N. Protective effect of ginsenosides $\operatorname{Rg}(2)$ and $\mathrm{Rh}(1)$ on oxidation-induced impairment of erythrocyte membrane properties. Biorheology 2008;45:689-700.

118. Li XT, Chen R, Jin LM, Chen HY. Regulation on energy metabolism and protection on mitochondria of Panax ginseng polysaccharide. Am J Chin Med 2009;37:11391152.

119. Li J, Ichikawa T, Jin Y, Hofseth LJ, Nagarkatti P, Nagarkatti M, Windust A, Cui T. An essential role of Nrf2 in American ginseng-mediated anti-oxidative actions in car- diomyocytes. J Ethnopharmacol 2010;130:222-230.

120. Fu Y, Ji LL. Chronic ginseng consumption attenuates age-associated oxidative stress in rats. J Nutr 2003; 133:3603-3609.

121. Chen X. Cardiovascular protection by ginsenosides and their nitric oxide releasing action. Clin Exp Pharmacol Physiol 1996;23:728-732.

122. Zhou W, Chai H, Lin PH, Lumsden AB, Yao Q, Chen C. Ginsenoside $\mathrm{Rb}_{1}$ blocks homocysteine-induced endothelial dysfunction in porcine coronary arteries. J Vasc Surg 2005;41:861-868.

123. Wang X, Chai H, Yao Q, Chen C. Molecular mechanisms of HIV protease inhibitor-induced endothelial dysfunction. J Acquir Immune Defic Syndr 2007;44:493-499.

124. Xie JT, Shao ZH, Vanden Hoek TL, Chang WT, Li J, Mehendale S, Wang CZ, Hsu CW, Becker LB, Yin JJ et al. Antioxidant effects of ginsenoside Re in cardiomyocytes. Eur J Pharmacol 2006;532:201-207.

125. Deng HL, Zhang JT. Anti-lipid peroxilative effect of ginsenoside $\mathrm{Rb}_{1}$ and $\mathrm{Rg}_{1}$. Chin Med J (Engl) 1991;104:395398.

126. Lim JH, Wen TC, Matsuda S, Tanaka J, Maeda N, Peng $\mathrm{H}$, Aburaya J, Ishihara K, Sakanaka M. Protection of ischemic hippocampal neurons by ginsenoside $\mathrm{Rb}_{1}$, a main ingredient of ginseng root. Neurosci Res 1997;28:191200.

127. Tian J, Fu F, Geng M, Jiang Y, Yang J, Jiang W, Wang C, Liu K. Neuroprotective effect of 20(S)-ginsenoside $\mathrm{Rg}_{3}$ on cerebral ischemia in rats. Neurosci Lett 2005;374:9297.

128. Lu JM, Yao Q, Chen C. Ginseng compounds: an update on their molecular mechanisms and medical applications. Curr Vasc Pharmacol 2009; 7:293-302. 